\title{
The toxicity of BDE-47 to the photosystem of Lemna minor fronds
}

\author{
N.W. QIU ${ }^{1}$, W.R. ZHANG ${ }^{1}$, X.H. YAN ${ }^{1}$, R.J. WANG ${ }^{1}$, L. TIAN ${ }^{*}$, G.L. HAN², and F. ZHOU ${ }^{3 *}$ \\ College of Life Sciences, Qufu Normal University, Qufu, Shandong 273165, P.R. China ${ }^{1}$ \\ Shandong Provincial Key Laboratory of Plant Stress, Shandong Normal University, Jinan 250014, P.R. China 2 \\ School of Food Science, Nanjing Xiaozhuang University, Nanjing 211171, P.R. China ${ }^{3}$
}

\begin{abstract}
To elucidate the toxicity of 2,2',4,4'-tetrabromodiphenyl ether (BDE-47) on photosynthetic primary processes, in vivo and in vitro treatments of BDE-47 were performed. The 20 -d treatment in vivo $\left(5-20 \mu \mathrm{g} \mathrm{dm}^{-3}\right)$ suppressed the reproduction of duckweed (Lemna minor) and led to decline in chlorophyll (Chl) content of fronds. The most obvious features of BDE47-treated fronds included a $\mathrm{Chl} a$ fluorescence rise at the $\mathrm{J}$ phase and a depression at the $\mathrm{G}$ phase, whereas significant fluorescence rises at the $\mathrm{L}, \mathrm{K}$, and $\mathrm{J}$ phases were found on the $\Delta \mathrm{V}_{\mathrm{t}}$ curve of thylakoid membranes treated with $10-15 \mathrm{mg} \mathrm{dm}^{-3}$ BDE-47 for $4 \mathrm{~h}$ (in vitro). In both in vivo and in vitro experiments, the BDE-47 treatments significantly reduced the density of the active reaction centers $\left(\mathrm{RC} / \mathrm{CS}_{\mathrm{o}}\right.$ ), affected the efficiency and speed of photosynthetic electron transfer [the maximum quantum yield of photosystem (PS) II photochemistry $-F_{v} / F_{m}$, quantum yield for electron transport $($ at $t=0)-\varphi_{\text {Eo }}$, electron transport flux per excited cross section $-\mathrm{ET}_{\mathrm{o}} / \mathrm{CS}_{\mathrm{o}}$, and net rate of reaction centers closure at 300 and $100 \mu \mathrm{s}-\mathrm{dV} / \mathrm{dt}_{\mathrm{o}}$ and $\mathrm{dVG} / \mathrm{dt}_{\mathrm{o}}$, respectively], and increased energy dissipation [quantum yield for energy dissipation $($ at $\mathrm{t}=0)-\varphi_{\mathrm{Do}}$, dissipated energy flux per reaction center - $\mathrm{DI}_{\mathrm{o}} / \mathrm{RC}$, and issipated energy flux per excited cross section - $\mathrm{DI}_{\mathrm{o}} / \mathrm{CS}_{\mathrm{o}}$ ]. The $\mathrm{BDE}-47$ at $5-15 \mathrm{mg} \mathrm{dm}^{-3}$ had no impact on the minimum (initial) fluorescence $\left(\mathrm{F}_{\mathrm{o}}\right)$ and total electron carriers per reaction center $\left(\mathrm{S}_{\mathrm{m}}\right)$ of the thylakoid membranes, but PS II units were less tightly grouped (a positive L-band). On the contrary, there was no positive L-band on the difference between relative fluorescence intensities of the normalized induction curves from $50 \mu \mathrm{s}$ to $300 \mu \mathrm{s}\left(\mathrm{W}_{\mathrm{K}}\right)$ of each BDE-47 treatment and control $\left(\Delta \mathrm{W}_{\mathrm{K}}\right)$, and $\mathrm{F}_{\mathrm{o}}$ and $\mathrm{S}_{\mathrm{m}}$ increased after the treatment with BDE-47. The above results indicate that BDE-47 not only affected the permeability of thylakoid membranes, but also relaxed the structure of PS II, thereby affecting the function of PS II. In addition, BDE-47 could induce secondary damage to the PSs in duckweed fronds.
\end{abstract}

Additional key words: chlorophyll a fluorescence, duckweed, energy dissipation, photosynthetic electron transfer, thylakoids.

\section{Introduction}

Polybrominated diphenyl ethers (PBDEs) are a group of additive brominated flame retardants, widely used in polymer-based commodities and daily necessities (Alaee et al. 2003, Watanabe et al. 2003). Because PBDEs are not chemically bonded to polymer products, they are easily separate from the surface of these products during their service life and penetrate into the environment (De Wit et al. 2002, Sjödin et al. 2003). As lipophilic and persistent organic compounds, PBDEs have bioaccumulation and significant biotoxicity, posing a great threat to animals and plants (Bragigand et al. 2006, Lee and Kim 2015). There are many studies on the animal toxicity of PBDEs, whereas the studies of phytotoxicity have only been carried out in recent years. Current studies indicate that PBDEs are significantly toxic to most plants, such as algae, aquatic plants, terrestrial plants and crops (Källqvist et al. 2006, Xie et al. 2013, Xu et al. 2015, Chen et al. 2018, Farzana et al. 2018). The PBDEs with low brominated degree are more soluble in water than those with high brominated degree. Therefore, low brominated diphenyl ethers are more easily absorbed by cells and are more toxic to plants; they can inhibit plant growth and development (Bragigand et al. 2006, Huang et al. 2011). So far, the mechanism of plant detoxification of PBDEs is still unclear.

The toxicity mechanism of PBDEs was found to be through directly damaging the membranes and interfering

Submitted 14 April 2020, last revision 9 June, accepted 10 June 2020.

Abbreviations: BDE-47 - 2,2',4,4'-tetrabromodiphenyl ether; Chl - chlorophyll; CK - control; CS - cross section; DMF - N,Ndimethylformamide; LHC - light-harvesting complex; PBDE - polybrominated diphenyl ether; PEA - plant efficiency analyser; $\mathrm{Q}_{\mathrm{A}}, \mathrm{Q}_{\mathrm{B}}$, $\mathrm{PQ}$ - plastoquinone in different states; PS - photosystem; RC - reaction center; ROS - reactive oxygen species.

Acknowledgements: This work was supported by the National Key Research and Development Project (No. 2019YFC1605800), the National Natural Science Foundation of China (Grant No. 31971503) and the Open Fund of Shandong Provincial Key Laboratory of Plant Stress (Projects No. KF201801). The first two authors contributed equally to this work.

* Corresponding authors; e-mails: tianlister@163.com, zhoufeng@njxzc.edu.cn 
with the electron transfer in photosynthesis and respiration, which led to electron leakage and the production of reactive oxygen species (ROS) (Pereira et al. 2013, Meng et al. 2018a). Under pollution stresses, chloroplasts are the major organelles in plant cells that produce ROS. Overproduction of ROS induced by PBDE treatments, in turn, damages the structure of chloroplasts (Zhang et al. 2013) and affects the photosystem (PS) II activity (Zhao et al. 2017). The toxicity of PBDEs to photosystem was first reported in microalgae. It was later discovered that PBDEs are also toxic to the photosystem of higher plants (Meng et al. 2018a). The above studies were performed to investigate the long-term and simple effect of PBDE on photosystems. The direct toxicity of PBDEs to photosynthetic processes and its toxicant mechanism remains unclear.

The 2,2',4,4'-tetrabromodiphenyl ether (BDE-47) is a predominant PBDE in water (Mhadhbi et al. 2012). Lemna minor as an aquatic model plant is widely used in water pollution research. Therefore, we used Lemna minor as the experimental plant to analyze the toxicity of BDE-47 to photosynthetic processes in this study. Chlorophyll (Chl) $a$ fluorescence induction is a sensitive, rapid and noninvasive experimental technique that is widely used in photosynthesis research. We analyzed the specific toxicity of BDE-47 to PS II by measuring Chl $a$ fluorescence induction curves and fluorescence parameters of Lemna minor.

\section{Materials and methods}

Plant hydroponics and treatment: The duckweed (Lemna minor L.) plants were collected from a constructed river in Qufu City, China. Duckweed plants were incubated in the dishes (12 cm in diameter and $2.5 \mathrm{~cm}$ in height) containing $150 \mathrm{~cm}^{3}$ of Hoagland nutrient solution. The dishes were placed in a growth chamber at a temperature of $25 \pm 1{ }^{\circ} \mathrm{C}$, a 16-h photoperiod, and irradiance of $150 \mu \mathrm{mol} \mathrm{m} \mathrm{m}^{-2} \mathrm{~s}^{-1}$ (white light provided by LED lamps). At the beginning of BDE-47 treatments, 10 uniform duckweed plants were cultured in each dish. The dishes contained $150 \mathrm{~cm}^{3}$ of Hoagland solution with 0 (the control - CK), 5, 10, 15, and $20 \mu \mathrm{g} \mathrm{dm}^{-3} \mathrm{BDE}-47$ (in vivo experiment), respectively. BDE-47 (GC/MS certified, purity $>99.9 \%$ ) was purchased from the German AccuStandard and dissolved with $\mathrm{N}, \mathrm{N}$-dimethylformamide (DMF) into a $1 \mathrm{mg} \mathrm{cm}^{-3}$ stock solution. The no-observed-effect concentration of DMF for duckweed is $2 \%(\mathrm{v} / \mathrm{v})$. So the DMF concentration in all treatment solution was formulated to $1 \%$. The solution in the dish was renewed in half every $2 \mathrm{~d}$ to keep a stable concentration of BDE-47. Each BDE-47 treatment had six replicates. The duckweed plants were harvested after 20-d treatments of BDE-47 for measurement of growth, Chl content and $\mathrm{Chl} a$ fluorescence induction. In addition, a certain amount of duckweed plants under control condition were cultivated for the extraction of thylakoid membranes.

Growth and Chl content assays: The growth inhibitory effect of BDE-47 on duckweed was defined as the number of duckweed plants per dish. The fronds Chl was extracted with $80 \%(\mathrm{v} / \mathrm{v})$ acetone. The Chl content was calculated according to absorbances at 663.6 and $646.6 \mathrm{~nm}$ (Porra 2002).

Extraction and treatment of thylakoid membranes: Thylakoid membranes were extracted from the duckweed fronds untreated by BDE-47 (Berthold et al. 1981). The fronds were dark adapted for $30 \mathrm{~min}$ before extraction. The extracted thylakoid membranes were suspended in a preservation solution containing $20 \mathrm{mM}$ methanesulfonic acid (MES), $0.4 \mathrm{M}$ sucrose, and $15 \mathrm{mM} \mathrm{NaCl}, \mathrm{pH}$ 6.5). The stock solution of BDE-47 was added to the thylakoid membranes for BDE treatment at $0{ }^{\circ} \mathrm{C}$. The final treatment concentrations of BDE-47 in the thylakoid membrane suspension were $0(\mathrm{CK}), 5,10,15$, and $20 \mathrm{mg} \mathrm{dm}^{-3}$, respectively (in vitro experiment). The chlorophyll (Chl) concentration of all the BDE-47-treated thylakoid membrane suspension was $1 \mathrm{mg} \mathrm{cm}^{-3}$. After the BDE-47 treatment for $4 \mathrm{~h}$, Chl $a$ fluorescence induction kinetics were determined immediately by a Handy PEA (Plant Efficiency Analyser, Hansatech Instrument, Norfolk, UK). The thylakoid membrane suspension $\left(1 \mathrm{~cm}^{3}\right)$ was used in a specific tube for each measurement. All measurement processes above were performed at $0-4{ }^{\circ} \mathrm{C}$ and a green radiation of about $2 \mu \mathrm{mol} \mathrm{m} \mathrm{m}^{-2} \mathrm{~s}^{-1}$.

Analysis of fluorescence induction curves: The fluorescence curves of the fronds and thylakoid membranes were measured with a Handy PEA at room temperature. The homogeneous red radiation $(650 \mathrm{~nm}$, $2500 \mu \mathrm{mol} \mathrm{m} \mathrm{m}^{-2} \mathrm{~s}^{-1}$ ) provided by an LED array was focused onto the sample (the diameter was $4 \mathrm{~mm}$ ). The intensity was sufficient to generate maximum fluorescence $\left(F_{m}\right)$ for all BDE-47-treated samples. The duckweed plants were given dark adaptation of $1 \mathrm{~h}$ before the measurement. The thylakoid membrane preparations were kept in the dark until the measurement was completed. The digitized data and fluorescence parameters derived from the fluorescence curves (O-J-I-P transient) were analyzed using the Biolyzer HP3 software of PEA (University of Geneva, Switzerland). Definition of fluorescence parameters: $F_{t}$ actual fluorescence at any time; $F_{o}-$ minimum (initial) fluorescence; $F_{v}$ - variable fluorescence, $F_{v}=\left(F_{m}-F_{o}\right) ; F_{v} /$ $\mathrm{F}_{\mathrm{m}}$ - maximum quantum yield of PS II photochemistry; $\mathrm{dV} / \mathrm{dt}_{\mathrm{o}}$ and $\mathrm{dVG} / \mathrm{dt}_{\mathrm{o}}$ - net rate of reaction centers (RCs) closure at 300 and $100 \mu \mathrm{s}$, respectively; $\psi_{\mathrm{o}}$ - efficiency that a trapped exciton moves an electron into the electron transport chain beyond the primary acceptor $\mathrm{Q}_{\mathrm{A}} ; \varphi_{\mathrm{Eo}}-$ quantum yield for electron transport $($ at $t=0) ; \varphi_{(D o)}$ - quantum yield for energy dissipation $($ at $\mathrm{t}=0) ; \mathrm{S}_{\mathrm{m}}$ - total electron carriers per RC $\left(\mathrm{ABS} / \mathrm{TR}_{\mathrm{o}} / \mathrm{ET}_{\mathrm{o}} / \mathrm{DI}_{\mathrm{o}}\right) / \mathrm{RC}$ - absorption flux / trapped energy flux / electron transport flux / dissipated energy flux, respectively, per $\mathrm{RC}$; $\left(\mathrm{RC} / \mathrm{TR}_{\mathrm{o}} / \mathrm{ET}_{\mathrm{o}} / \mathrm{DI}_{\mathrm{o}}\right) / \mathrm{CS}_{\mathrm{o}}$ - density of RCs ( $\mathrm{Q}_{\mathrm{A}}$-reducing PS II reaction centers) / trapped energy flux / electron transport flux / dissipated energy flux, respectively, per excited cross section (CS); $\mathrm{PI}_{\mathrm{abs}}$ - performance index; $\mathrm{SFI}_{\mathrm{abs}}$ - structure function index; $\mathrm{DF}$ - total driving force for photochemical activity; $\mathrm{V}_{\mathrm{t}}$ relative fluorescence intensity of normalized induction curves from $\mathrm{O}$ phase to $\mathrm{P}$ phase, $\mathrm{V}_{\mathrm{t}}=\left(\mathrm{F}_{\mathrm{t}}-\mathrm{F}_{\mathrm{o}}\right) /\left(\mathrm{F}_{\mathrm{m}}-\mathrm{F}_{\mathrm{o}}\right)$, 
$\Delta \mathrm{V}_{\mathrm{t}}=\mathrm{V}_{\mathrm{t}}($ each BDE-47 treatment $)-\mathrm{V}_{\mathrm{t}}(\mathrm{CK}) ; \mathrm{W}_{\mathrm{K}}$ - relative fluorescence intensity of normalized induction curves from $50 \mu \mathrm{s}$ to $300 \mu \mathrm{s}, \mathrm{W}_{\mathrm{K}}=\left(\mathrm{F}_{\mathrm{t}}-\mathrm{F}_{\mathrm{o}}\right) /\left(\mathrm{F}_{300 \mu \mathrm{s}}-\mathrm{F}_{\mathrm{o}}\right), \Delta \mathrm{W}_{\mathrm{K}}$ $=\mathrm{W}_{\mathrm{K}}\left(\right.$ each BDE-47 treatment) $-\mathrm{W}_{\mathrm{K}}(\mathrm{CK})$ (Strasser et al. 2004, Jiang et al. 2009, Guha et al. 2013).

Statistical analyses: Significance analysis among different

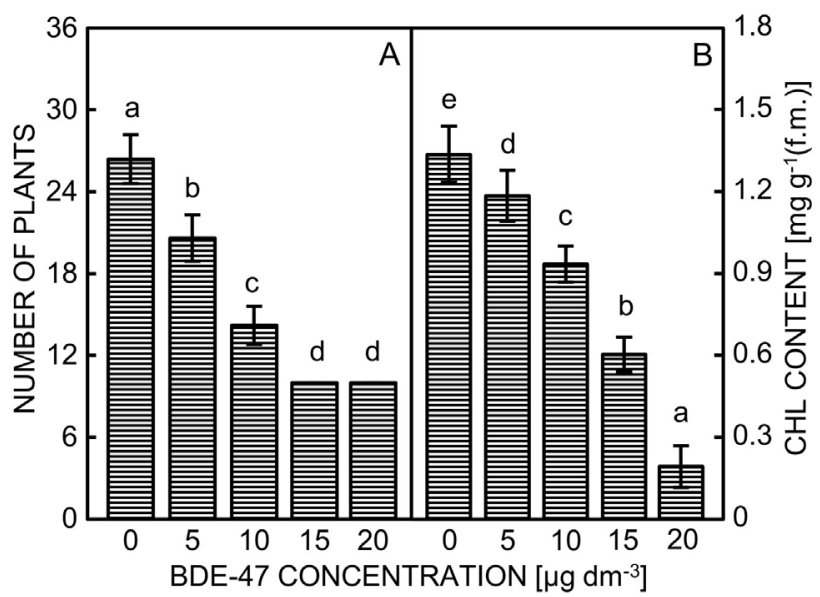

Fig. 1. Reproduction $(A)$ and frond chlorophyll content $(B)$ of duckweed plants treated with $0,5,10,15$, and $20 \mu \mathrm{g} \mathrm{dm}{ }^{-3}$ BDE-47 for $20 \mathrm{~d}$. Means \pm SDs, $n=6$. Different letters denote significant differences $(P<0.05)$.
BDE-47 treatments was analyzed by one-way $A N O V A$ and Duncan's multiple comparison. Different superscript letters in the figures denote significant differences $(P<0.05)$ among BDE-47 treatments. All the statistic calculation was processed by the SPSS 17.0 software.

\section{Results}

At the beginning of the BDE-47 treatments, ten duckweed plants were cultured in each dish. After a 20-d exposure to $0,5,10,15$, and $20 \mu \mathrm{g} \mathrm{dm}^{-3} \mathrm{BDE}-47$, the mean number of duckweed plants in each dish was 26.4, 20.6, 14.2, 10 and 10, respectively (Fig. 1A). The results proved that $5-20 \mu \mathrm{g} \mathrm{dm}{ }^{-3}$ BDE-47 significantly inhibited the reproduction of duckweed. At high concentrations of BDE$47\left(15-20 \mu \mathrm{g} \mathrm{dm}^{-3}\right)$, duckweed plants could not reproduce. The duckweed plants treated by BDE-47 also showed obvious poisoning symptoms. After 20-d treatments of $5-20 \mu \mathrm{g} \mathrm{dm}^{-3}$ BDE-47, the Chl content in duckweed fronds was declined to $88.5,69.9,45.2$, and $14.4 \%$ of the control fronds, respectively (Fig. $1 B$ ). The duckweed fronds turned yellow obviously under $15-20 \mu \mathrm{g} \mathrm{dm}$ BDE-47 for $20 \mathrm{~d}$, suggesting that BDE-47 has significantly toxic to the photosynthetic system of duckweed.

Chlorophyll $a$ fluorescence transient is a highly sensitive tool to monitor various stresses, and often used to describe

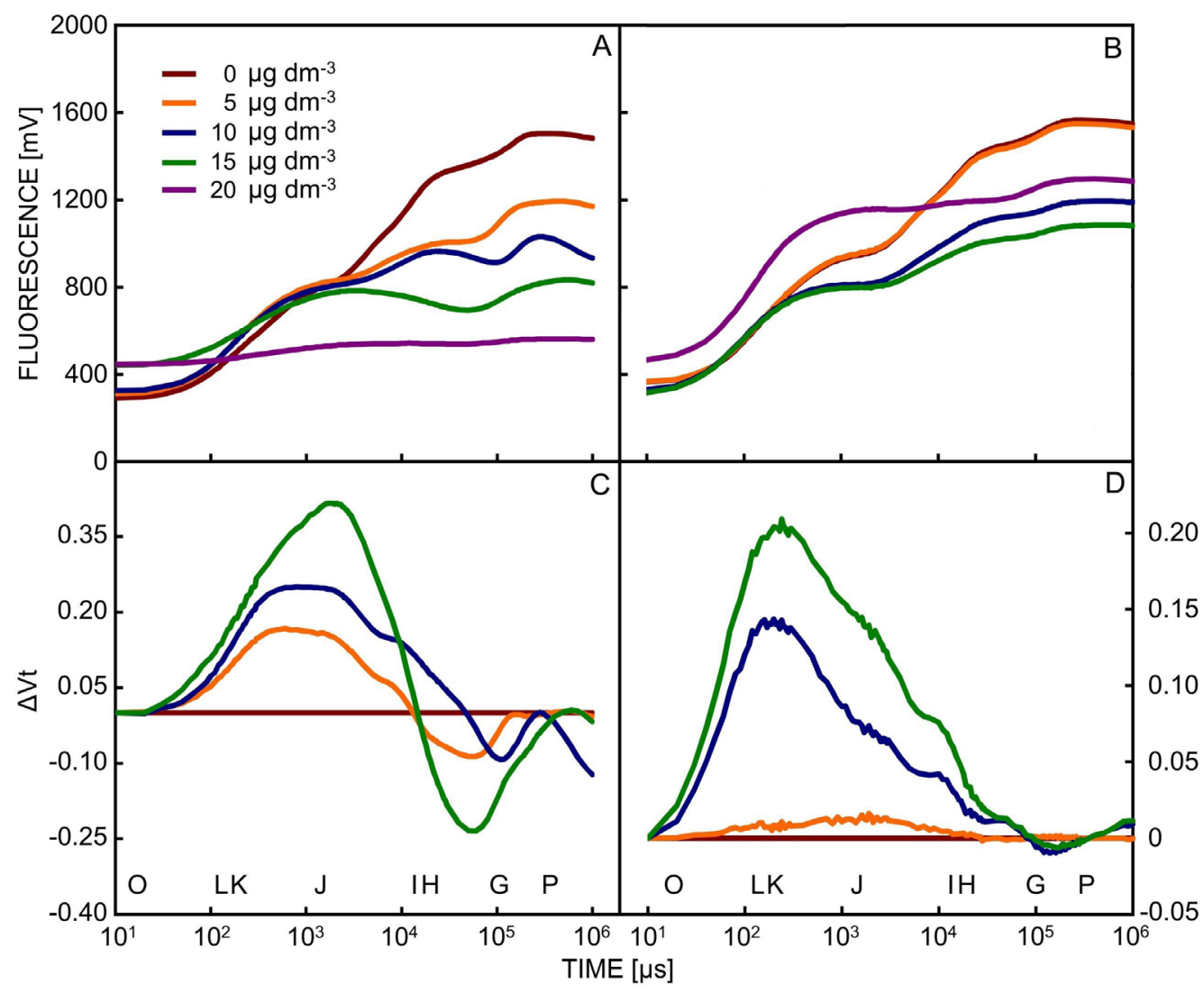

Fig. 2. Characteristic changes in chlorophyll $a$ fluorescence curves of duckweed fronds $(A$ and $C)$ and thylakoid membranes $(B$ and $D)$ exposed to BDE-47 treatment. Each curve is the mean curve of 10 replicates. $V_{t}=\left(F_{t}-F_{o}\right) /\left(F_{m}-F_{o}\right), \Delta V_{t}=V_{t}($ each BDE-47 treatment $)-$ $\mathrm{V}_{\mathrm{t}}$ (control); the values of $\mathrm{V}_{\mathrm{t}}$ (control) are all assumed to be zero (Jiang et al. 2008). 


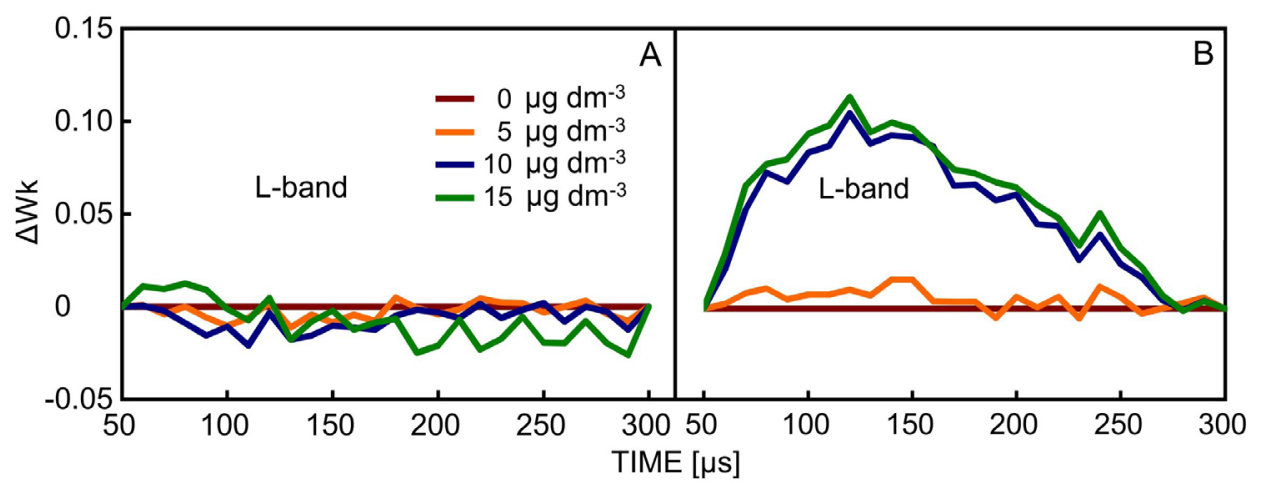

Fig. 3. Characteristic changes in $\left(\Delta \mathrm{W}_{\mathrm{K}}\right)$ curves of duckweed fronds $(A)$ and thylakoid membranes $(B)$ exposed to BDE-47 treatment. Each $\Delta \mathrm{W}_{\mathrm{K}}$ curve is the mean curve of 10 replicates. $\mathrm{W}_{\mathrm{K}}=\left(\mathrm{F}_{\mathrm{t}}-\mathrm{F}_{\mathrm{o}}\right) /\left(\mathrm{F}_{300}\right.$ us $\left.-\mathrm{F}_{\mathrm{o}}\right), \Delta \mathrm{W}_{\mathrm{K}}=\mathrm{W}_{\mathrm{K}}($ each BDE-47 treatment $)-\mathrm{W}_{\mathrm{K}}($ control $)$; the values of $\mathrm{W}_{\mathrm{K}}$ (control) are all assumed to be zero (Jiang et al. 2008).

the state of PS II under these stresses (Kalaji et al. 2016, Stirbet et al. 2018). The O-J phase reflects the transfer of electrons from pheo to $\mathrm{Q}_{\mathrm{A}^{-}}$. The $\mathrm{J}$-I phase represents the electron transfer from $\mathrm{Q}_{\mathrm{A}}^{-}$to $\mathrm{Q}_{\mathrm{B}}$, and the I phase $(\mathrm{I}, \mathrm{H}$, and $\mathrm{G}$ phase) means the accumulation of $\mathrm{Q}_{\mathrm{A}}{ }^{-} \mathrm{Q}_{\mathrm{B}}{ }^{2-}$. The I-P phase denotes electron transfer from $\mathrm{Q}_{\mathrm{B}}{ }^{2-}$ to $\mathrm{PQ}$. All PQs are reduced to $\mathrm{PQH}_{2}$ at the $\mathrm{P}$ phase. Both in vivo and in vitro fluorescence experiments proved that BDE-47 has significant toxicity to duckweed photosynthetic system. After a treatment of $5-20 \mu \mathrm{g} \mathrm{dm}^{-3}$ BDE-47 for $20 \mathrm{~d}$, the fluorescence at I phase and P phase on the original OJIP curves of the fronds declined as the BDE-47 concentration increase, while the fluorescence at $\mathrm{O}$ phase increased. The most noticeable feature on the original curves of the BDE47 treated fronds was the appearance of a depression near the $\mathrm{G}$ phase. The original curve of the fronds turned into a straight line under $20 \mu \mathrm{g} \mathrm{dm}{ }^{-3}$ BDE-47 (Fig. 2A).

After a treatment with $10-15 \mathrm{mg} \mathrm{dm}^{-3} \mathrm{BDE}-47$ for $4 \mathrm{~h}$, the original OJIP curve of thylakoid membranes also changed significantly. The fluorescence at I phase and $P$ phase of the OJIP curves of the thylakoid membranes declined with BDE-47 concentration rising. However, the fluorescence at $\mathrm{O}$ phase did not increase after BDE47 treatment. The original fluorescence curve of thylakoid membranes treated by $20 \mathrm{mg} \mathrm{dm}^{-3}$ BDE-47 lost the typical OJIP rising trend. The fluorescence of the $\mathrm{O}$ phase increased significantly, and there was no significant increase from J phase to I phase, indicating that PS II electron transfer was significantly blocked under $20 \mathrm{mg} \mathrm{dm}^{-3}$ BDE-47 for $4 \mathrm{~h}$. Furthermore, there was no depression at the $\mathrm{G}$ phase on the original fluorescence curve of the BDE-47-treated thylakoid membranes. The above results indicate that the direct toxicity and chronic toxicity of BDE-47 to the photosystem were significantly different (Fig. $2 B$ ).

To observe the distinct changes among the fluorescence curves of different BDE-47 treatment, the normalized OJIP curves from $\mathrm{O}$ phase to $\mathrm{P}$ phase $\left(\mathrm{V}_{\mathrm{t}}\right)$ are presented in Figs. $2 C$ and $2 D$. Compared with the control curve, the characteristic of the $\Delta \mathrm{V}_{\mathrm{t}}$ curve of the fronds treated by BDE-47 included a significantly increased $\mathrm{J}$ phase and a markedly depressed $G$ phase. The higher the BDE-47 concentration, the higher the J-phase uplifted (Fig. 2C). With reference to the control curve, the L, K, and $\mathrm{J}$ phases were all uplifted in the $\Delta \mathrm{V}_{\mathrm{t}}$ curves of the BDE-47-treated thylakoid membranes, but no significant change was observed at the $G$ phase. The higher the BDE-47 concentration, the higher the L-, K- and J-phases uplifted, too (Fig. 2D). The presence of a K-band on the $\Delta \mathrm{V}_{\mathrm{t}}$ curves of the thylakoid membranes treated with BDE47 indicated that the activity of oxygen-evolving complex (OEC) was affected. In summary, it is speculated that, when the accumulation content of BDE-47 in the thylakoid membranes is low, the electron transfer of PS II-donor side is affected first. As the cumulative content of BDE-47 rose, the entire electron transfer of PS II would be affected.

To make the $\mathrm{L}$ phase more distinctive, $\Delta \mathrm{W}_{\mathrm{K}}$ curves (from $\mathrm{O}$ to $\mathrm{K}$ phase) of different BDE-47 treatments was calculated (Fig. 3). With reference to the control curve, no L-phase uplift (L-band) appeared on the $\Delta \mathrm{W}_{\mathrm{K}}$ curve of the fronds treated by BDE-47 (Fig. 3A). However, an obvious L-band at $100-150 \mu \mathrm{s}$ appeared on the $\Delta \mathrm{W}_{\mathrm{K}}$ curve of thylakoid membranes treated by $10-15 \mathrm{mg} \mathrm{dm}^{-3}$ BDE-47 (Fig. $3 B$ ). Positive L-band denoted that the PS II units were less tightly grouped compared with the control sample (Strasser et al. 2004).

We deduced twenty fluorescence parameters from the original OJIP curves. To observe the behavior of each fluorescence parameter, its value was normalized against the control value. By comparing the differences in fluorescence parameters between BDE- 47 treated fronds (Fig. 4A) and thylakoid membranes (Fig. 4B), we could understand the effects of BDE-47 on PS II photosynthetic primary processes. In both the fronds and thylakoid membranes, BDE-47 resulted in an increase in $\mathrm{dV} / \mathrm{dt}_{0}$, $\mathrm{dVG} / \mathrm{dt}_{\mathrm{o}}, \varphi_{\mathrm{Do}}, \mathrm{DI}_{\mathrm{o}} / \mathrm{CS}_{\mathrm{o}}, \mathrm{ABS} / \mathrm{RC}, \mathrm{TR}_{\mathrm{o}} / \mathrm{RC}, \mathrm{DI}_{\mathrm{o}} / \mathrm{RC}$, and a decline in $\mathrm{F}_{\mathrm{m}}, \mathrm{F}_{\mathrm{v}} / \mathrm{F}_{\mathrm{m}}, \psi_{\mathrm{o}}, \varphi_{\mathrm{Eo}}, \mathrm{RC} / \mathrm{CS}_{\mathrm{o}}, \mathrm{TR}_{\mathrm{o}} / \mathrm{CS}_{\mathrm{o}}, \mathrm{ET}_{\mathrm{o}} /$ $\mathrm{CS}_{\mathrm{o}}, \mathrm{PI}_{\mathrm{abs}}, \mathrm{SFI}_{\mathrm{abs}}, \mathrm{DF}$. The increased $\mathrm{dV} / \mathrm{dt}_{\mathrm{o}}$ and $\mathrm{dVG} / \mathrm{dt}_{\mathrm{o}}$ indicated that BDE-47 affected the electron transfer rate of PS II donor side. Due to the decrease of RCs density $\left(\mathrm{RC} / \mathrm{CS}_{\mathrm{o}}\right)$ and trapped energy flux per excited cross section $\left(\mathrm{TR}_{\mathrm{o}} / \mathrm{CS}_{\mathrm{o}}\right)$, absorption flux and trapped energy flux per $\mathrm{RC}$ $\left(\mathrm{ABS} / \mathrm{RC}, \mathrm{TR}_{\mathrm{o}} / \mathrm{RC}\right)$ increased. The BDE-47 treatments reduced the electron transport efficiency $\left(\psi_{\mathrm{o}}\right)$ and quantum yield $\left(\mathrm{F}_{\mathrm{v}} / \mathrm{F}_{\mathrm{m}}, \varphi_{\mathrm{Eo}}, \mathrm{ET}_{\mathrm{o}} / \mathrm{CS}_{\mathrm{o}}\right)$ of duckweed fronds and thylakoid membranes, and increased the proportion of dissipated energy flux $\left(\varphi_{\mathrm{Do}}, \mathrm{DI}_{\mathrm{o}} / \mathrm{RC}, \mathrm{DI}_{\mathrm{o}} / \mathrm{CS}_{\mathrm{o}}\right)$. Therefore, 

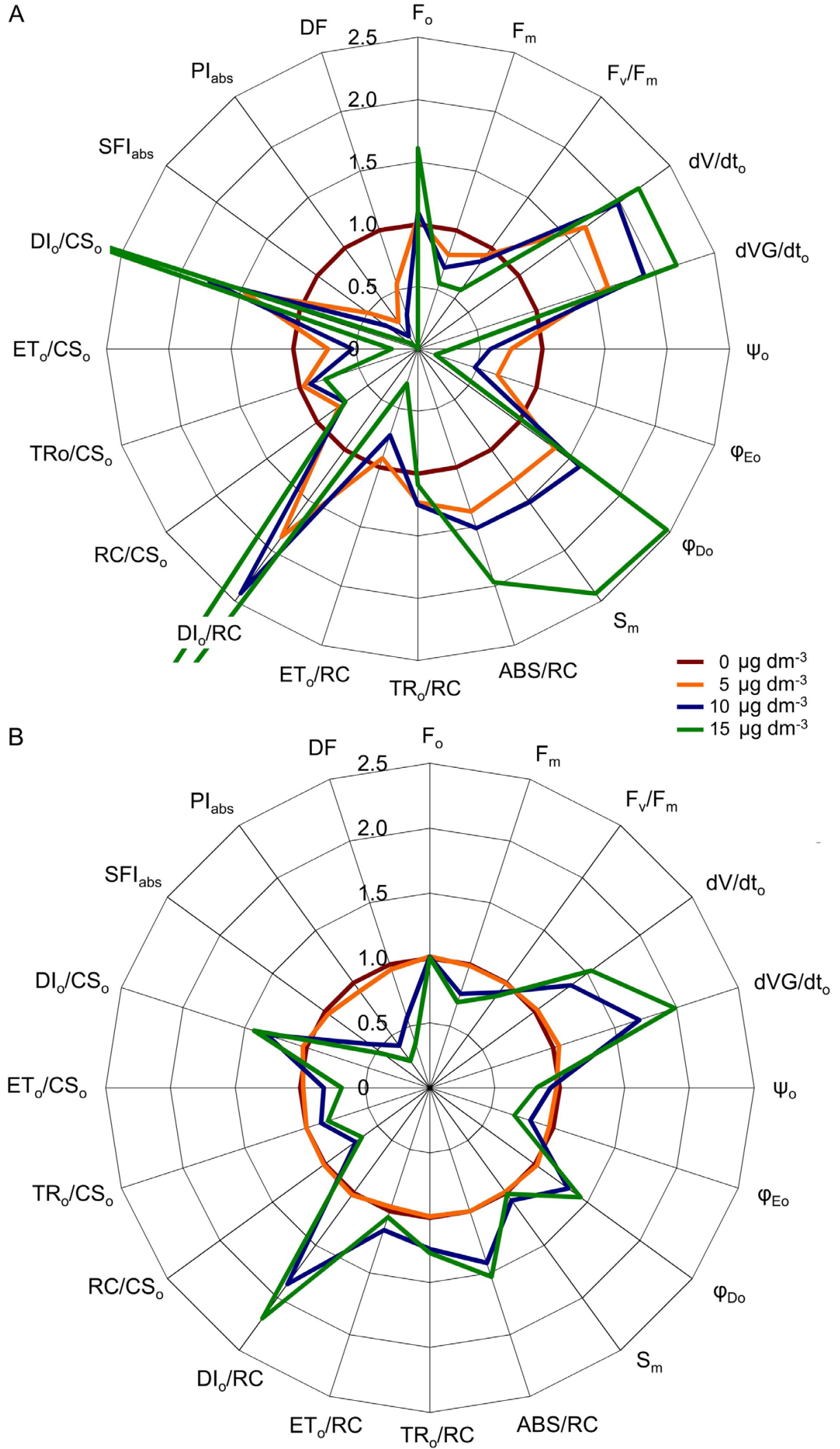

Fig. 4. A radar plot of fluorescence parameters of duckweed fronds $(A)$ and thylakoid membranes $(B)$ exposed to BDE-47 stress. All the parameters were calculated according to the OJIP curves. Means of 10 replicates. The values of all fluorescence parameters of the control are all assumed to be 1.0, and the data are the ratio of the BDE-47 treatment value to the control value. 
performance index (PI), structure function index (SFI) and the total driving force (DF) of duckweed fronds or thylakoid membranes all decreased after exposure to BDE-47. The above results prove that BDE-47 has both direct and indirect toxicity to the PSII of duckweed.

Meanwhile, there were obvious differences in fluorescence parameters between in vitro and in vivo experiments. With reference to the control parameters, the treatment of $5 \mathrm{mg} \mathrm{dm}^{-3}$ BDE-47 had little effect on all fluorescence parameters of duckweed thylakoid membranes; 10 - $15 \mathrm{mg} \mathrm{dm}^{-3}$ BDE-47 had little effect on the $\mathrm{F}_{\mathrm{o}}$ and $\mathrm{S}_{\mathrm{m}}$, but slightly increased the $\mathrm{ET}_{\mathrm{o}} / \mathrm{RC}$. In contrast, BDE-47 treatments $\left(5-15 \mu \mathrm{g} \mathrm{dm}^{-3}\right)$ obviously increased the $\mathrm{F}_{\mathrm{o}}$ and $\mathrm{S}_{\mathrm{m}}$ of duckweed fronds and decreased the $\mathrm{ET}_{\mathrm{o}} /$ RC. Hence, the chronic toxicity of BDE-47 to the PS II of fronds are also significantly different from the direct toxicity of BDE-47 to the PS II of thylakoid membranes.

\section{Discussion}

BDE-47 has prominent toxicity to plants at very low concentration (0.1 - $\left.100 \mu \mathrm{g} \mathrm{dm}^{-3}\right)$ (Meng et al. 2018b). The results in this paper found that $5-20 \mu \mathrm{g} \mathrm{dm}{ }^{-3}$ BDE47 reduced the Chl content in duckweed fronds (Fig. 1), suggesting that the BDE-47 has prominent effects on the photosynthesis of duckweed fronds.

In order to analyze the direct and indirect toxicity of BDE-47 to photosystems, a comparison of Chl a fluorescence transients was conducted between the in vitro and in vivo experiments (Fig. 2). The most obvious feature of the fluorescence curve of the in vivo experiments included a fluorescence rise at $\mathrm{J}$ phase and a depression at $\mathrm{G}$ phase with reference to the control curve (Figs. $2 A$ and $2 C)$. The rise at $\mathrm{J}$ phase implied that the electron transfer from $\mathrm{Q}_{\mathrm{A}}{ }^{-}$to $\mathrm{Q}_{\mathrm{B}}$ was blocked $\left(\mathrm{Q}_{\mathrm{A}}{ }^{-}\right.$accumulation) (Schansker et al. 2014). G-phase depression may be related to ascorbic acid, which can supply sufficient electrons to PS II donor side (Mano et al. 2014). G-phase depression also occurs in heat-treated barley leaves (Tóth et al. 2007). However, G-phase depression did not appear on the OJIP curves of BDE-47 treated thylakoid membranes, because there was no ascorbate in the in vitro experiment solution. The ascorbate content in chloroplasts of $\mathrm{C}_{3}$ plants was as high as $20-25 \mathrm{mM}$, which can be continuously regenerated through the ascorbic acid-glutathione cycle. When thylakoid membranes were damaged, a large amount of ascorbic acid could enter the lumen of the thylakoid to supply electrons to PS II. In the in vitro experiments, a significant fluorescence rise was also observed at $\mathrm{L}$ and $\mathrm{K}$ phase on the $\Delta \mathrm{V}_{\mathrm{t}}$ curve of thylakoid membranes exposed to $10-15 \mathrm{mg} \mathrm{dm}^{-3}$ BDE-47 (Fig. 2D), and a significant L-band was observed on the $\Delta \mathrm{W}_{\mathrm{K}}$ curve (Fig. $3 B$ ). The $\mathrm{K}$ peak suggested that OECs were damaged by BDE-47. L-band indicated that BDE-47 weakened the energetic connectivity among photosynthetic units (Srivastava et al. 1997). After a 4-h treatment of $20 \mathrm{mg} \mathrm{dm}^{-3}$ BDE-47, the fluorescence at $\mathrm{O}, \mathrm{L}, \mathrm{K}$ and $\mathrm{J}$ phases on the original OJIP curve of thylakoid membranes increased significantly compared with that of the thylakoid membranes treated with 5 - $15 \mathrm{mg} \mathrm{dm}^{-3}$ BDE-47, demonstrating that PS II units could be directly damaged by BDE-47 (Fig. 2B). No obvious L-band and $\mathrm{K}$ peak appeared in the in vivo experiments after the treatment of $5-15 \mu \mathrm{g} \mathrm{dm}{ }^{-3}$ BDE-47 for $20 \mathrm{~d}$ (Fig. $3 A$ ), but the duckweed fronds yellowed and the PS II activity decreased, indicating that BDE-47 also has indirect toxicity to PS II.

In vivo and in vitro experiments have confirmed that the direct toxicity and chronic toxicity of BDE-47 to PS II were mostly similar. The absorption and trap of light energy, the rate and efficiency of electron transfer, and quantum yield were all affected by BDE-47 in both experiments (Fig. 4). BDE-47 (5 - $\left.15 \mathrm{mg} \mathrm{dm}^{-3}\right)$ showed little effect on $F_{o}$ and $S_{m}$ of thylakoid membranes, indicating that BDE-47 at these concentrations did not affect the light-harvesting complex (LHC) and the redox equilibrium between $\mathrm{Q}_{\mathrm{A}}$ and $\mathrm{Q}_{\mathrm{B}}$ (Fig. 4B) (Strasser et al. 2004). Furthermore, $5 \mathrm{mg} \mathrm{dm}^{-3}$ BDE-47 treatment had little effect on all fluorescence parameters of thylakoid membranes. However, the $20 \mathrm{mg} \mathrm{dm}^{-3}$ BDE-47 treatment could dissociate LHC from PS II complex and increase $\mathrm{F}_{\mathrm{o}}$ (Fig. 2B). The results above indicate the BDE-47 toxicity to thylakoid membranes is dose-dependent. BDE-47 would produce direct toxicity to thylakoid membranes only when the accumulation concentration reaches a certain level. For the fronds, BDE-47 treatment $\left(5-15 \mu \mathrm{g} \mathrm{dm}^{-3}\right)$ increased the $\mathrm{F}_{\mathrm{o}}$ and $\mathrm{S}_{\mathrm{m}}$ (Fig. 4A). Hence, a long-term BDE-47 treatment would cause dissociation of LHC in fronds and increase the multiple turnover of $\mathrm{Q}_{\mathrm{A}}$ reduction events (Guha et al. 2013). As a lipophilic compound like polycyclic aromatic hydrocarbons, BDE-47 may disrupt the biomembrane permeability and the structure of PS II complex by acting on the membrane lipids (Kreslavski et al. 2017). In living leaves with BDE-47 damaged PS II, excessive electrons could escape from the photosynthetic electron transport chain of PS II, producing ROS in chloroplasts. ROS would destroy the structure of photosystem by attacking biomembranes and biomacromolecules, leading to plant death in severe cases.

\section{Conclusions}

The results in this paper reveal that $\mathrm{Chl} a$ fluorescence kinetics can be used to detect the consistency and the distinction between the chronic toxicity and direct toxicity of BDE-47 to duckweed photosystem. BDE-47 can accumulate on biomembranes, and its toxicity to thylakoid membranes are dose-dependent. When accumulating to a certain concentration, BDE-47 can disrupt the permeability of the thylakoid membranes. At the same time, BDE-47 can relax the structure of PS II complex and weaken the connectivity among the photosynthetic units. Our results are helpful for understanding the phytotoxicity of PBDEs.

\section{References}

Alaee, M., Arias, P., Sjödin, A., Bergman, A.: An overview of commercially used brominated flame retardants, their 
applications, their use patterns in different countries/regions and possible modes of release. - Environ. Int. 29: 683-689, 2003.

Berthold, D.A., Babcock, G.T., Yocum, C.F.: A highly resolved, oxygen-evolving photosystem II preparation from spinach thylakoid membranes: EPR and electron-transport properties. - FEBS Lett. 134: 231-234, 1981.

Bragigand, V., Amiard-Triquet, C., Parlier, E., Boury, P., Marchand, P., Hourch, M.E.: Influence of biological and ecological factors on the bioaccumulation of polybrominated diphenyl ethers in aquatic food webs from French estuaries. Sci. total Environ. 368: 615-626, 2006.

Chen, J., Li, K., Le, X.C., Zhu, L.Z.: Metabolomic analysis of two rice (Oryza sativa) varieties exposed to 2,2',4,4'-tetrabromodiphenyl ether. - Environ. Pollut. 237: 308-317, 2018.

De Wit, C.A .: An overview of brominated flame retardants in the environment. - Chemosphere 46: 583-624, 2002.

Farzana, S., Tam, N.F.Y.: A combined effect of polybrominated diphenyl ether and aquaculture effluent on growth and antioxidative response of mangrove plants. - Chemosphere 201: 483-491, 2018

Guha, A., Sengupta, D., Reddy, A.R.: Polyphasic chlorophyll $a$ fluorescence kinetics and leaf protein analyses to track dynamics of photosynthetic performance in mulberry during progressive drought. - J. Photochem. Photobiol. B 119: 71-83, 2013.

Huang, H., Zhang, S., Christie, P.: Plant uptake and dissipation of PBDEs in the soils of electronic. - Environ. Pollut. 159: 238-243, 2011.

Jiang, H.X., Chen, L.S., Zheng, J.G., Han, S., Tang, N., Smith, B.R.: Aluminum-induced effects on photosystem II photochemistry in Citrus leaves assessed by the chlorophyll $a$ fluorescence transient. - Tree Physiol. 28: 1863-1871, 2008.

Jiang, H.X., Tang, N., Zheng, J.G., Chen, L.S.: Antagonistic actions of boron against inhibitory effects of aluminum toxicity on growth, $\mathrm{CO}_{2}$ assimilation, ribulose-1,5-bisphosphate carboxylase/oxygenase, and photosynthetic electron transport probed by the JIP-test, of Citrus grandis seedlings. - BMC Plant Biol. 9: 102, 2009.

Kalaji, H.M., Jajoo, A., Oukarroum, A., Brestic, M., Zivcak, M., Samborska, I.A., Cetner, M.D., Łukasik, L., Goltsev, V., Ladle, R.J.: Chlorophyll $a$ fluorescence as a tool to monitor physiological status of plants under abiotic stress conditions. - Acta Physiol. Plant. 38: 102, 2016.

Källqvist, T., Grung, M., Tollefsen, K.E.: Chronic toxicity of $2,4,2^{\prime}, 4^{\prime}$-tetrabromodiphenyl ether on the marine alga Skeletonema costatum and the crustacean Daphnia magna. Environ. Toxicol. Chem. 25: 1657-1662, 2006.

Kreslavski, V.D., Brestic, M., Zharmukhamedov, S.K., Luybimov, V.Y., Lankin, A.V., Jajoo, A., Allakhverdiev, S.I.: Mechanisms of inhibitory effects of polycyclic aromatic hydrocarbons in the photosynthetic primary processes in pea leaves and thylakoid preparations. - Plant Biol. 19: 683-688, 2017.

Lee, H.J., Kim, G.B.: An overview of polybrominated diphenyl ethers (PBDEs) in the marine environment. - Ocean Sci. J. 50: 119-142, 2015.

Mano, J., Hideg, É., Asada, K.: Ascorbate in thylakoid lumen functions as an alternative electron donor to photosystem II and to photosystem I. - Arch. Biochem. Biophys. 429: 71-80, 2004.

Meng, Y.T., Liu, B.L., Zhang, P., Cui, P., Song, Y.G.,
Qiu, N.W., Han, G.L., Zhou, F.: Toxic effects of 2,2',4,4'-tetrabromodiphenyl ether on Chinese cabbage. HortScience 53: 1930-1935, $2018 \mathrm{a}$.

Meng, Y.T., Zhang, W.R., Wang, J., Jiang, D.C., Qiu, N.W., Wang, R.J.: [Research progress of plant toxicology of polybrominated diphenyl ethers (PBDEs).] - Plant Physiol. J. 54: 183-191, 2018b. [In Chin.]

Mhadhbi, L., Fumega, J., Beiras, R.: Toxicological effects of three polybromodiphenyl ethers (BDE-47, BDE-99 and BDE154) on growth of marine algae Isochrysis galbana. - Water Air Soil Pollut. 223: 4007-4016, 2012.

Pereira, L.C., De Souza, A.O., Dorta, D.J.: Polybrominated diphenyl ether congener (BDE-100) induces mitochondrial impairment. - Basic clin. pharmacol. Toxicol. 112: 418-424, 2013.

Porra, R.J.: The chequered history of the development and use of simultaneous equations for the accurate determination of chlorophylls $a$ and $b$. - Photosynth. Res. 73: 149-156, 2002.

Schansker, G., Tóth, S.Z., Holzwarth, A.R., Garab, G.: Chlorophyll $a$ fluorescence: beyond the limits of the $\mathrm{Q}_{\mathrm{A}}$ model. - Photosynth. Res. 120: 43-58, 2014.

Sjödin, A., Patterson, D.G., Jr., Bergman, Å.: A review on human exposure to brominated flame retardants - particularly polybrominated diphenyl ethers. - Environ. Int. 29: 829-839, 2003.

Srivastava, A., Guisse, B., Greppin, H., Strasser, R.J.: Regulation of antenna structure and electron transport in photosystem II of Pisum sativum under elevated temperature probed by the fast polyphasic chlorophyll $a$ fluorescence transient: OKJIP. Biochim. biophys. Acta 1320: 95-106, 1997.

Stirbet, A., Lazár, D., Kromdijk, J., Govindjee : Chlorophyll a fluorescence induction: can just a one-second measurement be used to quantify abiotic stress responses? - Photosynthetica 56: 86-104, 2018.

Strasser, R.J., Tsimilli-Michael, M., Srivastava, A.: Analysis of the chlorophyll $a$ fluorescence transient. - In: Papageorgiou, G.C., Govindjee (ed.): Chlorophyll $a$ fluorescence: a signature of photosynthesis. Pp. 321-362, Springer, Dordrecht 2004.

Tóth, S.Z., Schansker, G., Garab, G., Strasser, R.J.: Photosynthetic electron transport activity in heat-treated barley leaves: the role of internal alternative electron donors to photosystem II. - Biochim. biophys. Acta 1767: 295-305, 2007.

Watanabe, I., Sakai, S.: Environmental release and behavior of brominated flame retardants. - Environ. Int. 29: 665-682, 2003.

Xie, X.C., Qian, Y., Xue, Y.G., He, H., Wei, D.Y.: Plant uptake and phytotoxicity of decabromodiphenyl ether (BDE-209) in ryegrass (Lolium perenne L.). - Environ. Sci. Process Impacts 15: 1904-1912, 2013.

Xu, X.H., Huang, H.L., Wen, B., Wang, S., Zhang, S.Z.: Phytotoxicity of brominated diphenyl ether-47 (BDE-47) and its hydroxylated and methoxylated analogues (6-OH-BDE-47 and 6-MeO-BDE-47) to maize (Zea mays L.). - Chem. Res. Toxicol. 28: 510-517, 2015.

Zhang, X.X., Tang, X.X., Zhou, B., Wang, Y.: Effects of decabromodiphenyl ether (BDE-209) on inter-specific competition between two species of marine bloom-forming microalgae. - PLoS ONE 8: e56084, 2013.

Zhao, Y., Wang, Y., Li, Y.J., Santschi, P.H., Quigg, A.: Response of photosynthesis and the antioxidant defense system of two microalgae species (Alexandrium minutum and Dunaliella salina) to the toxicity of BDE-47. - Mar. Pollut. Bull. 124: 459-469, 2017. 